\title{
RANCANG BANGUN SENSOR RADAR SENSE AND AVOID UAV UNTUK SMART SYSTEM TELETRANSPORT ALAT KESEHATAN
}

\author{
Agus Hendra Wahyudi*1 \\ ${ }^{1}$ Pusat Teknologi Dirgantara LAPAN \\ Email: 1agus.hendra@lapan.go.id, ${ }^{1}$ agus8hendra@gmail.com \\ *Penulis Korespondensi
}

(Naskah masuk: 29 November 2020, diterima untuk diterbitkan: 21 Juli 2021)

\begin{abstract}
Abstrak
Perancangan sensor radar untuk sense and avoid (SAA) sistem pesawat tanpa awak (UAV) bertujuan agar operasi teletransport alat kesehatan dengan UAV VTOL berjalan dengan aman terhindar dari kecelakaan tabrakan di udara. Sensor radar ini didesain dengan bahan duroid 5880 dengan dielektrik konstant 2.2 dan ketebalan subtrate $1.57 \mathrm{~mm}$. Bentuk antenna circular dan bekerja di pita ku-band 14 Ghz. Terdapat dua sensor untuk Tx dan Rx dalam satu substrate. Hasil simulasi sensor menunjukkan bandwitdh yang lebar $1.5 \mathrm{GHz}$ sehingga mampu menghasilkan resolusi range sangat baik yaitu $9.2 \mathrm{~cm}$. Penguatan antenna dihasilkan $7.32 \mathrm{~dB}$ dan sudut beamwidth sensor $83^{\circ}$ arah azimuth dan $78.2^{\circ}$ arah elevasi. Sensor ini akan disematkan pada sistem SAA dengan algoritma neural network yang mendrive manuever UAV VTOL berbelok kesamping pada sudut dan jarak yang tepat sehingga terhindar dari tabrakan dengan objek penghalang.
\end{abstract}

Kata kunci: Circular Patch antenna, Sense and avoid Radar Sensor, UAV, teletransport kesehatan, neural network.

\section{SENSE AND AVOID UAV RADAR SENSOR DESIGN FOR SMART SYSTEM TELETRANSPORT MEDICAL DEVICES}

\begin{abstract}
The design of the radar sensor for the sense and avoid (SAA) system of unmanned aircraft (UAV) aims to make teletransport operations of medical devices with UAV VTOL run safely avoiding collisions in the air. This radar sensor is designed with duroid 5880 material with a dielectric constant of 2.2 and a subtrate thickness of 1.57 $\mathrm{mm}$. The antenna is circular and works on the $14 \mathrm{Ghz}$ ku-band band. There are two sensors for Tx and Rx in one substrate. The sensor simulation results show a wide bandwidth of $1.5 \mathrm{GHz}$ so that it is able to produce a very good range resolution of $9.2 \mathrm{~cm}$. The antenna gain was $7.32 \mathrm{~dB}$ and the beamwidth angle of the sensor was $83^{O}$ in the azimuth direction and $78.2^{\circ}$ in the elevation direction. This sensor will be embedded in the SAA system with a neural network algorithm that drives the UAV VTOL maneuver to turn sideways at the right angle and distance so that it avoids collisions with obstructions.
\end{abstract}

Keywords: Circular Patch antenna, Sense and avoid Radar Sensor, UAV, health teletransport, neural network.

\section{PENDAHULUAN}

Pesawat tanpa awak banyak digunakan untuk kepentingan kebutuhan manusia misalnya remote sensing, ekologi, pertanian dan kesehatan (Anggraeni et al., 2020; Venkata Subba Rao and Gorantla, 2019; Tetuko et al., 2017; Sokač et al., 2016; Garcia-Fernandez et al., 2018). Dalam perkembangannya transport UAV juga semakin dirasakan keperluannya di Indonesia karena akses jalan yang sulit atau adanya kemacetan lalu lintas darat. Namun keamanan transportasi dengan pesawat tanpa awak menjadi syarat penting agar paket alat kesehatan yang akan disampaikan tepat pada waktunya dan terhindar dari kecelakaan saat diterbangkan diudara. Oleh karena itu pesawat ini harus dilengkapi dengan kemampuan dalam mendeteksi dan menghindari objek halangan sepanjang perjalanan menuju alamat tujuannya (sense and avoid (SAA) system) dan menjadi riset yang sangat penting (Zhahir, Razali and Mohd Ajir, 2016; Moore, 2019; Pham et al., 2015) .

Jenis UAV yang sesuai dengan keperluan teletransport kesehatan adalah vertika take off dan vertikal landing seperti quadrortor, ataupun fixed wing dengan kemampuan vtol (hybrida). UAV Vtol 
hibrida menggunakan engine bensin untuk mendorong maju uav dengan propulsinya sedangkan engine elektriknya untuk landing dan take off. UAV jenis ini sangat mudah untuk landing di atas rumahsakit atau puskesmas dengan landing pad yang dibuat khusus. Operator pilot pada masing-masing rumah sakit dan puskesmas sudah disiapkan terlebih dahulu untuk mengoperasikan teletransport. Walaupun begitu UAV vtol dilengkapi navigasi otomatis sesuai tujuan dan waypoint yang telah ditetapkan menggunakan GPS, IMU dan autopilot system.

Operasi teletranport kesehatan dengan UAV ini bekerja tidak hanya pada siang hari, keperluan teletrasnport harus bisa menjangkau malam hari. Oleh karena itu kemampuan sistem menghindar dan mendeteksi objek halangan harus bisa dilakukan siang maupaun malam. Sensor radar SAA mampu bekerja mendeteksi objek halangan di malam hari maupun saat terdapat awan dan kabut karena geloombang elektromagnetik yang dipancarkan olehnya memiliki panjang gelombang yang mampu menembus awan/asap dan tidak tergantung pada cahaya matahari.

Setelah mampu mendeteksi halangan baik jarak maupun kecepatannya dengan dilengkapi algoritma cerdas neural network pesawat mampu membuat keputusan logika manuever pesawat yang tepat sehingga tabrakan dengan objek bisa dihindari. Misalnya manuever belok/bank kiri dengan sudut tertentu diikuti bank kanan dengan sudut tertentu agar trajektory terbang tetap menuju sasaran alamat tujuan.

Mengingat ruang dan dimensi muatan UAV yang terbatas maka desain sensor radar SAA dilakukan pada frekuensi tinggi (Ku band) sehingga bentuk sensor menjadi kecil. Bentuk sensor sendiri dibuat mengunakan microstrip patch sehingga lebih mudah dibuat, bentuknya ceper serta beratnya ringan bisa menyesuaikan dengan kondisi UAV.

\section{PERANCANGAN SENSOR RADAR SAA}

Teletransport alat kesehatan dari satu rumah sakit ke rumah sakit yang lain atau puskesmas menggunakan UAV digambarkan pada skema berikut.

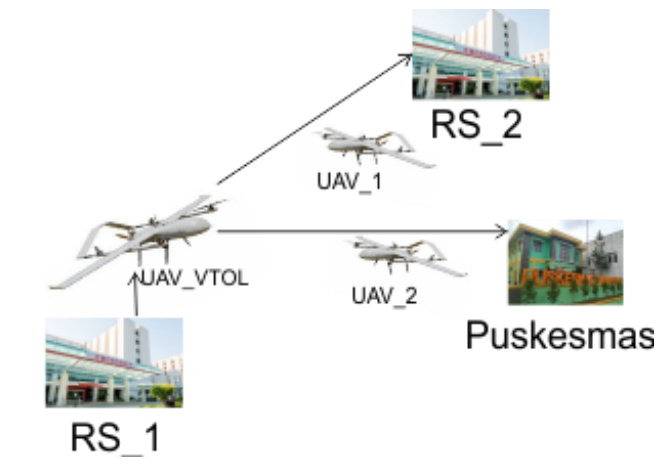

Gambar 1. Teletransport Alat Kesehatan dengan UAV VTOL
Pada gambar 1, UAV VTOL membawa alat kesehatan misalnya kit test covid 19 dari rumah sakit ke puskesmas atau ke Rumah sakit lainnya. Kit alat kesehatan yang dibawa disimpan dalam tabung muatan di dalam body UAV dan mudah untuk diambil. Berikutnya UAV akan diterbangkan kembali dengan take off secara vertikal dari landing pad menuju home. Akan tetapi, kondisi perjalanan UAV VTOL bisa jadi ada halangan ditengah jalan oleh UAV lain yang melintas atau objek terbang lainnya misalnya UAV_1 atau UAV_2 pada gambar diatas. Objek halangan ini perlu dihindari oleh UAV VTOL sehingga tidak terjadi tabrakan dengan dilengkapi radar pendeteksi halangan dan kemampuan menghindar (Sense and Avoid System).

Sensor radar SAA UAV ini berfungsi untuk mendeteksi halangan di depan jalur penerbangan UAV. Setelah mendeteksi baik jarak dan kecepatan halangan, SAA dengan algoritma neural network mengambil langkah aksi menghindar berbelok ke samping pada waktu dan sudut yang tepat sehingga tidak terjadi tabrakan dan misi teletransport alat kesehatan menjadi berhasil dengan baik.

Sensor radar SAA ini berupa antenna microstrip patch berbentuk lingkaran yang bekerja di frekuensi ku band. Perancangan ini menggunakan bahan duroid 5880 dengan dielektrik konstant $\left(\varepsilon_{\mathrm{r}}\right)$ 2.2 ketebalan (h) $0.157 \mathrm{~cm}$ pada frekuensi resonansi $\left(\mathrm{f}_{\mathrm{r}}\right) .14 \mathrm{Ghz}$. Dimensi antenna bisa ditentukan dari persamaan (1-2) berikut (Ballanis, 2016). :

$$
\begin{aligned}
& F=\frac{8.791 \times 10^{9}}{f_{r} \sqrt{\epsilon_{r}}} \\
& a=\frac{F}{\sqrt{1+\frac{2 h}{\pi \epsilon_{r} F}\left[\ln \left(\frac{\pi F}{2 h}+1.7726\right)\right]}}
\end{aligned}
$$

Dimensi jari-jari antenna (a) hasil perhitungan pada frekuensi resonansi $14 \mathrm{Ghz}$ dengan subtrate duroid sesuai persamaan diatas adalah $3.6502 \mathrm{~mm}$. Hasil perancangan antenna ditunjukkan pada gambar 2.

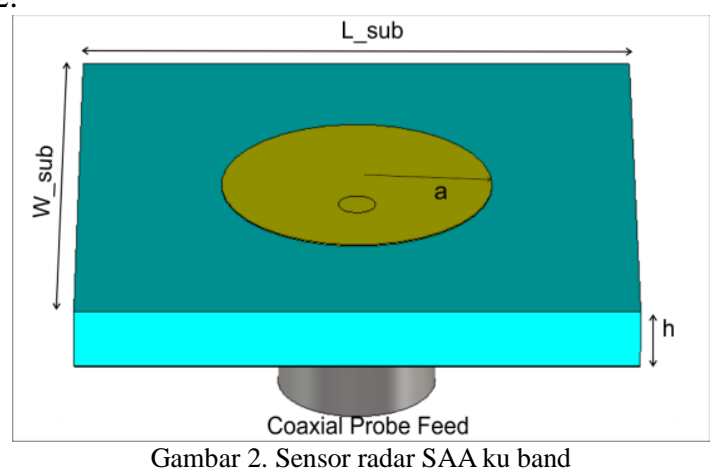

Pada gambar 2, lebar subtrate dan panjangnya adalah sama sebesar 4 jari-jari circular patch. Feeding probe coaxial ditempatkan sehingga memiliki impedance matching $50 \mathrm{ohm}$ sesuai input transmitter. Pada realisasinya nanti terdapat 2 antenna pada satu subtrate untuk transmitter dan satu lagi sebagai receiver seperti pada gambar 3 . 


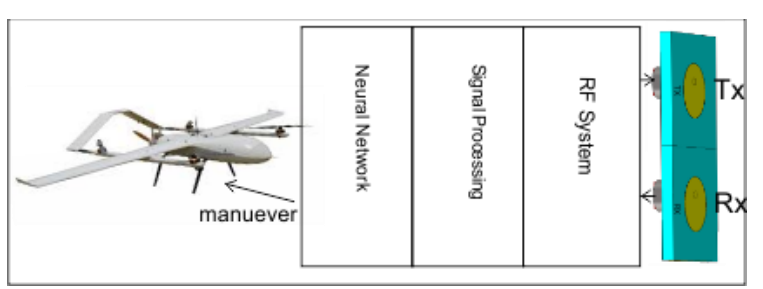

Gambar 3. Sensor dan Sistem radar SAA di UAV VTOL

Pada gambar 3, transmitter antenna memancarkan sinyal elektromagnetik ke arah target depan UAV. Sinyal ini berupa sinyal dengan modulasi Frekuensi yang linear. Pantulan sinyal dari objek akan terhamburkan dan sebagian diterima kembali oleh antenna receiver. Sinyal ini akan mengalami penguatan, filtering dan demodulasi di bagian RF system. Pada bagian sinyal processing sinyal akan diterjemahkan menjadi informasi jarak objek dan kecepatannya. Selanjutnya neural network akan mengambil keputusan berdasarkan logika manuever yang optimal sehingga menghindari tabrakan dengan objek.

\section{HASIL SIMULASI DAN PEMBAHASAN}

Selanjutnya desain antenna hasil perhitungan dibuat dengan menggunakan bahan subtrate duroid 5880 adapun detil parameter dalam desain circular patch antenna ku band untuk radar SAA dipaparkan dalam tabel 1 berikut :

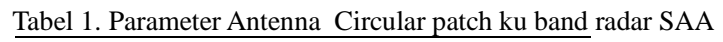

\begin{tabular}{ccc}
\hline Parameter & Nilai & symbol \\
\hline Dielektrik & 2.2 & $\varepsilon_{\mathrm{r}}$ \\
konstant & $0.157 \mathrm{~cm}$ & $\mathrm{~h}$ \\
Tebal subtrate & 0.0009 & Tan $\delta$ \\
Loss tangent & $0.36502 \mathrm{~cm}$ & $\mathrm{a}$ \\
Jari-jari patch & $2.92 \mathrm{~cm}$ & Lsub \\
Panjang subtrate & $1.46 \mathrm{~cm}$ & Wsub \\
Lebar subtrate & $1.46 \mathrm{~cm}$ & \\
Jarak antara Tx & & \\
dan RX sensor & &
\end{tabular}

\section{Bandwidth Sensor}

Bandwidth Sensor radar SAA didefinisikan berdasarkan kriteria $\mathrm{S} 11<-10$ dB. Hasil simulasi sensor dari frekuensi 13 sampai $15 \mathrm{GHz}$ ditunjukkan pada gambar 4.

Dari gambar S11 vs frekuensi antenna ini bisa bekerja dengan range frekuensi dari 13.222 $\mathrm{GHz}$ sampai $14.852 \mathrm{GHz}$. Dimana nilai fraksional banwidthnya adalah $11.6 \%$ dari frekuensi tengah. Jika bandwidth ini dipakai semua maka resolusi radar SAA bisa dihitung menggunakan persamaan 3 menjadi :

$$
\delta=\frac{c}{2 \beta}=\frac{30}{2 \times 1,63}=9.2 \mathrm{~cm}
$$

Dengan resolusi $9.2 \mathrm{~cm}$ radar SAA bisa mendeteksi UAV lainnya hingga burung yang terbang yang menjadi ancaman terjadinya tabrakan di udara. Range resolusi sebesar ini lebih bagus dibandingkan range resolusi requirement pada sensor SAA optik 20 meter (Forlenza, n.d.)

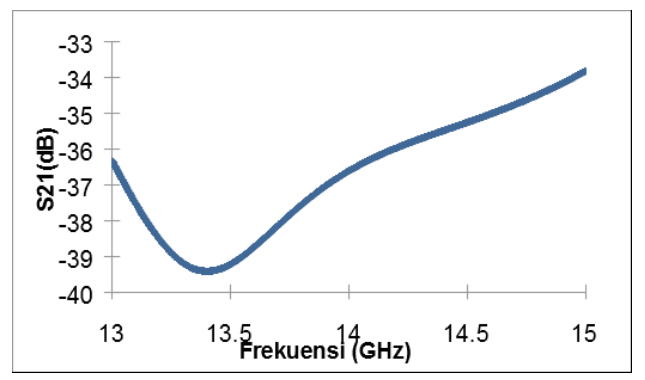

Gambar 4. Hasil Simulasi S11 vs Frekuensi

\section{Interferensi TX RX}

Antara Tx dan Rx dipisahkan dalam jarak 1.46 cm sebagaimana tabel 1. Daya pancar dari Tx tidak boleh masuk ke $\mathrm{Rx}$ sehingga tidak terhadi false detection. Hal ini bisa diketahui dengan hasil simulasi $\mathrm{S}$ parameter yaitu S21 dan S12 sebagaimana gambar 5 berikut :

Hasil simulasi antara S21 dan S12 nilainya sama dan berimpit sehingga pada gambar 5 ini hanya diwakili oleh S21 saja fungsi frekuensi. Jarak yang terlalu dekat dapat menimbulkan coupling antara satu antenna ke antenna yang lain sehingga menimbulkan interferensi gelombang elektromagnetik dimana hal ini bisa menimbulkan salah pengukuran jarak objek bahkan kerusakan pada alat RF system radar SAA.

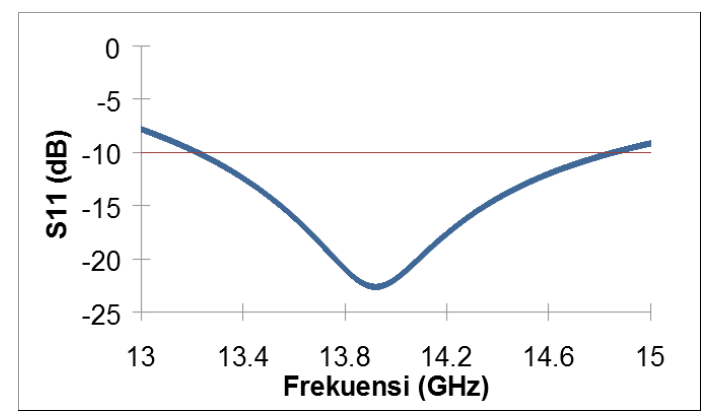

Gambar 5. Hasil Simulasi S21 vs Frekuensi

Tampak pada gambar 5 nilai S21 memiliki nilai dibawah $-33 \mathrm{~dB}$ yang menunjukkan antara TX dan RX tidak terjadi crosstalk atau interferensi sehingga false detection antar dua antenna ini tidak akan terjadi walaupun dibuat dalam satu subtrate dengan jarak $1.46 \mathrm{~cm}$.

\section{Pola Radiasi Sensor radar SAA}

Pola radiasi dari sensor radar SAA memiliki main lobe dan sidelobe serta backlobe. Mainlobe pada $3 \mathrm{~dB}$ atau power setengah akan digunakan dalam pendeteksian objek halangan. Hasil simulasi pola radiasi sensor pada frekuensi $14 \mathrm{GHz}$ ditunjukkan pada gambar 6 berikut : 


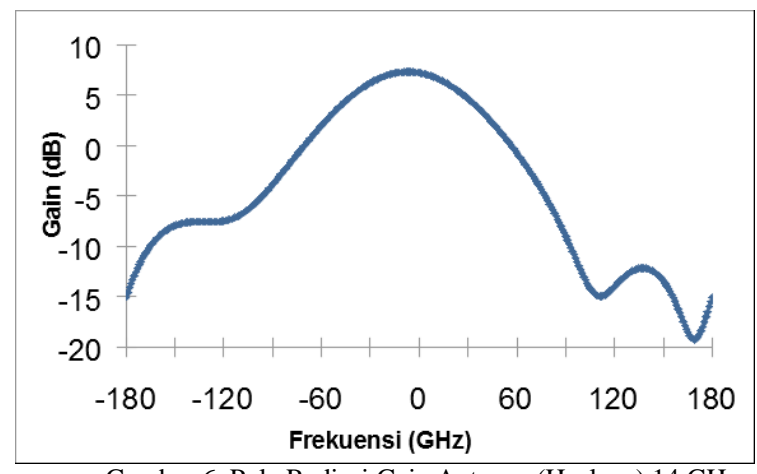

Gambar 6. Pola Radiasi Gain Antenna (H-plane) $14 \mathrm{GHz}$

Pada gambar 6 pola radiasi arah H-plane, memiliki sudut $3 \mathrm{~dB}$ beamwidth sebesar $78.2^{\mathrm{O}}$ dengan sidelobe $-14.9 \mathrm{~dB}$. Pada pola radiasi antenna arah E-plane gambar 7, besar gain di $14 \mathrm{GHz}$ adalah $7.32 \mathrm{~dB}$. Sudut $3 \mathrm{~dB}$ beamwidth sebesar $83^{\circ}$ dan sidelobenya adalah $-16 \mathrm{~dB}$.

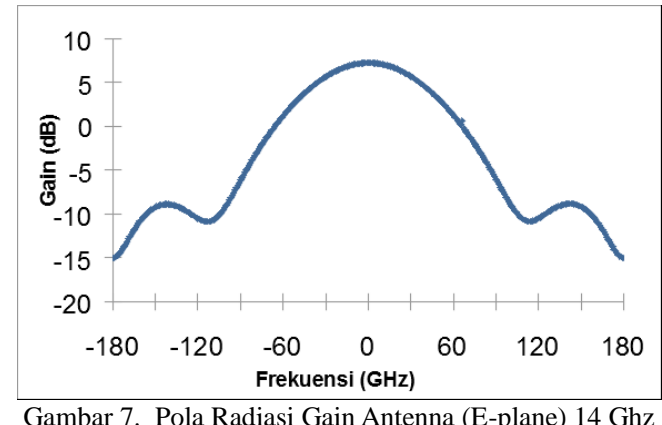

\section{KESIMPULAN}

Sensor radar SAA didesain menggunakan circular patch antenna ku band. Sensor memiliki bandwidth $1.5 \mathrm{GHz}$ menghasilkan resolusi range 9 cm cukup baik untuk mendeteksi objek penghalang UAV VTOL dalam melakukan misi di udara. Sudut beamwidth daya separuh digunakan oleh sensor dalam mendeteksi objek yaitu sebesar pada arah azimuth $83^{\circ}$ dan pada arah elevasi $78.2^{\circ}$. Antara Tx dan Rx sensor dipisahkan dengan jarak $1.46 \mathrm{~cm}$ dalam satu subtrate dan memiliki nilai isolasi yang cukup baik yaitu dibawah $-33 \mathrm{~dB}$. Penguatan sensor pada frekuensi ku band $14 \mathrm{GHz}$ adalah sebesar 7.32 dB. Sensor ini akan digunakan pada sistem radar SAA dalam mendeteksi objek penghalang baik jarak maupun kecepatannya, kemudian dengan neural network kendali system UAV VTOL bermanuever berbelok kesamping pada sudut dan waktu jarak yang tepat untuk menghindari tabrakan dengan objek lain didepannya.

\section{DAFTAR PUSTAKA}

ANGGRAENI, S., dkk, 2020. The Deployment of Drones in Sending Drugs and Patient Blood Samples COVID-19. Indonesian Journal of Science \& Technology, 5(2), pp.193-200.
BALLANIS, C.A., 2016. Antenna Theory, Analysis and Design. John Wiley and Son, New York.

FORLENZA, I.L., n.d. Vision based strategies for implementing Sense and Avoid capabilities onboard Unmanned Aerial Systems. UNIVERSITÀ DEGLI STUDI DI NAPOLI "FEDERICO II".

GARCIA-FERNANDEZ, M., dkk., 2018. UAVmounted GPR for NDT applications. 2018 15th European Radar Conference, EuRAD 2018, pp.2-5.

MOORE, E., 2019. Radar Detection, Tracking and Identification for UAV Sense and Avoid Applications. Electronic Theses and Dissertations. [online] Available at: <https://digitalcommons.du.edu/etd/1544>.

PHAM, H., dkk, 2015. A survey on unmanned aerial vehicle collision avoidance systems. [online] (1). Available at: <http://arxiv.org/abs/1508.07723>.

SOKAČ, M., dkk, S., 2016. UAV application in ecology: Data collecting with quad-copter equipped with Arduino based measurement platform. Proceedings Elmar International Symposium Electronics in Marine, 2016-Novem(September), pp.233236.

TETUKO, J., dkk., 2017. Development of circularly polarized synthetic aperture radar on-board UAV JX-1. International Journal of Remote Sensing, [online] 38(8-10), pp.2745-2756. Available at: <http://dx.doi.org/10.1080/01431161.2016. 1275057>.

VENKATA SUBBA RAO, P. \& GORANTLA, S.R., 2019. Design and Modelling of anAffordable UAV Based Pesticide Sprayer in Agriculture Applications. 5th International Conference on Electrical Energy Systems, ICEES 2019, 360(February), pp.1-4.Ballanis, C.A. (2016) Antenna Theory, Analysis and Design. John Wiley and Son, New York.

ZHAHIR, A., RAZALI, A. \& MOHD AJIR, M.R., 2016. Current development of UAV sense and avoid system. IOP Conference Series: Materials Science and Engineering, 152(1). 